\title{
Assessment of failure to the stator winding of the induction motor by means of deep neural network
}

\author{
Sebastian Kuroczycki ${ }^{1,}$, Konrad Górny ${ }^{1 *}$ and Wojciech Pietrowski ${ }^{1}$ \\ ${ }^{1}$ Institute of Electrical Engineering and Electronics, Poznan University of Technology, Poznan, Poland
}

\begin{abstract}
Due to the fact that inter-turn short-circuits are the ones of the most common causes of damage to stator of induction motors, research on their early detection is still gaining in importance. The scientific novelty in the presented article is an approach in which a decision element informing about the failure of stator of induction machine is a deep artificial neural network. In the learning process, torque waveforms subjected to a continuous wavelet transform were used. In order to classify of the stator winding failures the accelerator of artificial neural networks was used.
\end{abstract}

\section{Introduction}

Studies carried out in recent years show that induction motors are the most commonly used motors in industry. Nevertheless, as described in articles [1], these are motors of older generations whose maintenance procedures were neglected in many cases. The aforementioned negligence can lead to far-reaching consequences in the form of increasing costs of repairs of drive systems and even stopping the technological process. Therefore, due to the desire to maximize profits, more and more companies are reaching for solutions in the field of early and non-invasive diagnostics of drive systems.

By virtue of the industry's focus on the diagnostics of electric motors, more and more researchers are concerned with development of newer and more reliable diagnostic methods. What is described in more detail in articles [2,3]. Many studies devoted to the diagnostics of electrical machines show that the most common damage of stator of the induction motors are related to the inter-turn short-circuits [4]. Despite the initially low outflow of inter-turn short-circuits on the properties of the induction motor, due to their propagation the influence of inter-turn short-circuits on the operation of motors can significantly increase.

Due to the fact that the effects of inter-turn faults are visible in the waveforms of such values as current or torque of the motor, these signals can be used to failures identify. The most popular signal processing techniques used in the diagnosis of inter-turns short-circuits are: Fourier Transform as well as Wavelet Transform [3]. One of the problems related to the detection of inter-turn short-circuits at their early stage is the interpretation of the results of analysis of diagnostic signals. However, this problem can be solved by using elements of artificial intelligence [5].
The presented article focuses on the assessment of the technical condition of the stator of the induction motor based on the results of the wavelet analysis of the torque waveforms and applications of the deep neural networks (DNN). The analysis concerns damage at various stages. During the development of proprietary software, a neural network accelerator was used.

\section{Selected results}

In order to perform the task, a software to assess the technical condition of the stator of the induction motor was developed. In the classification process a convolutional neural network was used. During training phase to the training of deep neural network, a base consisting of images showing the motor torque waveforms for various degrees of damage to the stator winding was used.

To analyse the torque waveforms in a transient state, the Continuous Wavelet Transform described by the following formula was used:

$$
\gamma(\tau, s)=\int_{-\infty}^{+\infty} x(t) \frac{1}{\sqrt{s}} \psi^{*}\left(\frac{t-\tau}{s}\right) d t
$$

where: $\psi\left(\frac{t-\tau}{s}\right)$ is a mother wavelet, $*$ is a complex conjugation, $\mathrm{s}$ is a scale, $\tau$ is an offset.

The analysis was carried out for: various kinds of wavelets from $\mathrm{db} 1$ to $\mathrm{db} 9$, two values of load: 0 and 15 $\mathrm{Nm}$, various numbers of shorted-turns, from 0 to 55 . F As a result of the analysis we achieve full training dataset which consist of 180 different images.

The deep neural network has been tested for several training set sizes and incomplete database (without images for 55 shorted turns). The results of impact of set size on correctness of the answer are presented in Figures 1, 2 and Table 1. As can be seen in the case of a full database, the percentage of correct network

\footnotetext{
Corresponding author: konrad.gorny@put.poznan.pl
} 
responses was $99.4 \%$. and despite the reduction of the training base, the network responded with a correctness of over $90 \%$. Problems with correct inference are only in cases, where failure is at a very early-stage as shown in Fig.2.

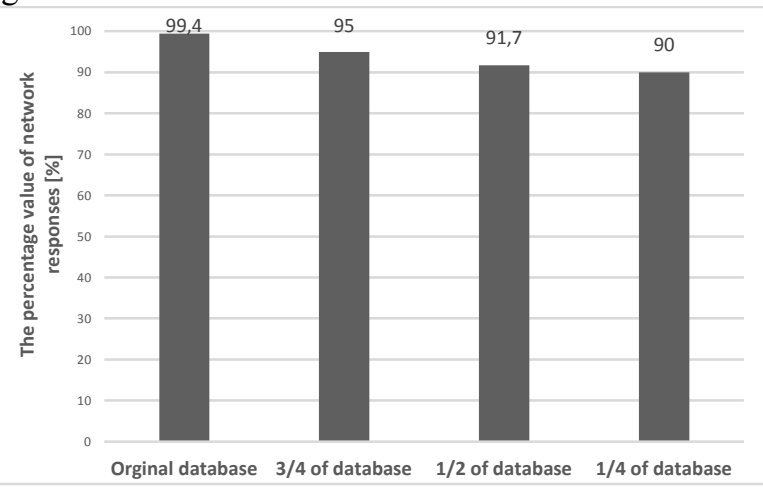

Fig. 1. Network responses for a different training dataset sizes.

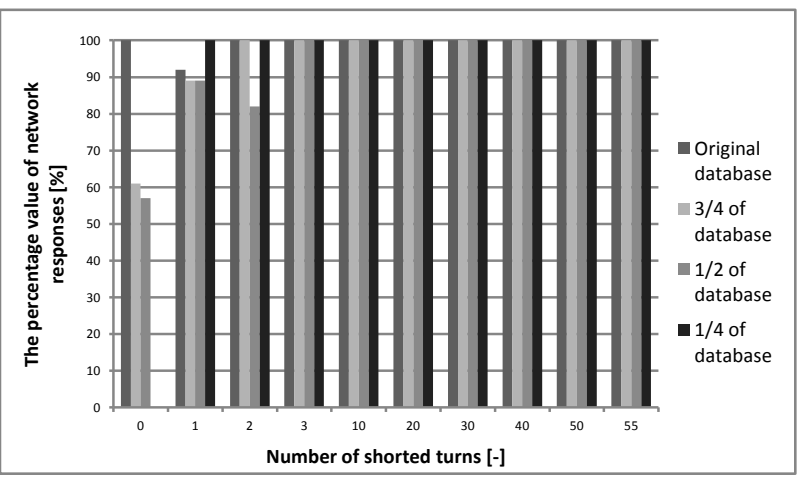

Fig. 2. Network responses for a different number of shorted turns.

Table 1. The results of inference for 55 shorted turns.

\begin{tabular}{|c|c|c|c|c|}
\hline $\mathbf{T}$ & Wavlet & $\begin{array}{c}\text { Number of } \\
\text { shorted turns }\end{array}$ & Results & $\begin{array}{c}\text { Time of } \\
\text { Inference }\end{array}$ \\
\hline$[\mathrm{Nm}]$ & {$[-]$} & {$[-]$} & {$[-]$} & {$[\mathrm{ms}]$} \\
\hline 0 & $\mathrm{db} 1$ & 55 & damaged & 94,95 \\
\hline 0 & $\mathrm{db} 2$ & 55 & damaged & 95,23 \\
\hline 0 & $\mathrm{db} 3$ & 55 & damaged & 94,55 \\
\hline 0 & $\mathrm{db} 4$ & 55 & damaged & 94,38 \\
\hline 0 & $\mathrm{db} 5$ & 55 & damaged & 94,81 \\
\hline 0 & $\mathrm{db} 6$ & 55 & damaged & 94,59 \\
\hline 0 & $\mathrm{db} 7$ & 55 & damaged & 94,91 \\
\hline 0 & $\mathrm{db} 8$ & 55 & damaged & 95,01 \\
\hline 0 & $\mathrm{db} 9$ & 55 & damaged & 95,22 \\
\hline 15 & $\mathrm{db} 1$ & 55 & damaged & 95,09 \\
\hline 15 & $\mathrm{db} 2$ & 55 & damaged & 115,82 \\
\hline 15 & $\mathrm{db} 3$ & 55 & damaged & 95,07 \\
\hline 15 & $\mathrm{db} 4$ & 55 & damaged & 95,04 \\
\hline 15 & $\mathrm{db} 5$ & 55 & damaged & 94,63 \\
\hline 15 & $\mathrm{db} 6$ & 55 & damaged & 94,7 \\
\hline
\end{tabular}

\begin{tabular}{|c|c|c|c|c|}
15 & $\mathrm{db} 7$ & 55 & damaged & 94,96 \\
\hline 15 & $\mathrm{db} 8$ & 55 & damaged & 94,99 \\
\hline 15 & $\mathrm{db} 9$ & 55 & damaged & 95,29 \\
\hline
\end{tabular}

The results presented in Table 1 show that DNN copes in the case of extrapolation.

\section{Summary}

The article presents a new method of diagnostics of electrical machines using deep neural networks. The results of inference about the failure of the stator circuit of the induction motor using the deep neural network as well as accelerator of artificial neural networks are presented. The convolutional neural network has been tested on the basis of the image database containing the results of the Continuous Wavelet Analysis of the torque waveforms of the induction motor. The article examines the influence of the size of the training base on the results of inference as well as the effectiveness of inferring the deep neural network from extrapolation issues. Based on the obtained results, it can be concluded that more advanced structures of neural networks such as deep neural networks can be successfully used in the diagnosis of induction motors. In addition, it can be assumed that the high efficiency of damage classification promises well for potential future implementations of deep neural networks in diagnostic systems.

\section{References}

1. E.S. Pandarakone, Y. Mizuno, H. Nakamura, IEEJ Journal of Industry Applications, Vol. 7 No. 6, 473478

2. J.S. Hsu, IEEE Trans. On Industrial Applications, Vol. 31, No. 5, 1016-1021

3. J. Cusido, L. Romeral, J.A. Ortega, J.A. Rosero, A. Garvia Espinosa, IEEE Trans. On Industrial Electronics, Vol. 55, No. 2, 663-643

4. S. Grubic, J.M. Aller, B. Lu, T.G. Habetler, IEEE Trans. on Industrial Electronics, Vol. 55, No. 12, 4127-4136

5. H. Su, K.T. Chong, R.R. Kumar, Neural Comput. Appl. 20 (2007), 183-194 